Physical Therapy Journal of Indonesia (PTJ) 2021, Volume 2, Number 2: 25-29

E-ISSN : 2722-6034 ; P-ISSN : 2722-0125

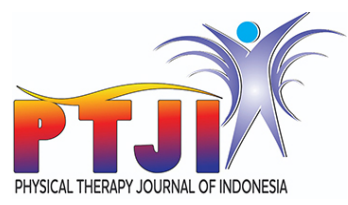

\title{
Physiotherapy Management on Anterior Cruciate Ligament (ACL) Reconstruction: A Case Report
}

\author{
Pande Komang Ute Ketiga ${ }^{1 *}$, Ferdi Perdana Putra ${ }^{1}$
}

'Bachelor and Professional Program of Physical Therapy, College of Medicine, Universitas Udayana
*Corresponding to: Pande Komang Ute Ketiga, Bachelor and Professional Program of Physical Therapy, College of Medicine, Universitas Udayana; uteketiga03@gmail.com
Received : 2021-08-15 Accepted : 2021-11-03 Published : 2021-12-02

\section{INTRODUCTION}

Anterior Cruciate Ligament (ACL) is one of knee's ligaments that stabilize knee passively. ACL prevent excessive anterior tibia translation. ACL with the posterior crutiatum ligament (PCL), medial collateral ligament (MCL) and lateral collateral ligament (LCL) as a passive stabilizer of the knee joint. But, ACL injury is one of the most common injuries which happen to athletes. ${ }^{1}$

ACL injuries often occur in sports activities which basically involve jumping, twisting and stopping movements. ${ }^{2}$ Approximately $50 \%$ of these injuries occur in the 15-25 years old who participate in high-speed sports. Approximately $30 \%$ of ACL injuries occur as a result of external loads. ACL rupture can cause knee joint instability complaints during activities. The long-term effects of knee instability can increase the risk of osteoarthritis. The incidence of ACL occurs in 38-78 people out of about 100,000 per year. $^{3}$

In acute injury conditions, it usually causes a popping sound followed by a sensation of pain, decreased range of motion of the joint, and instability in the knee joint. Examinations which help to determine the presence of a tear in the ACL are by performing several specific tests with complete tear of the right ACL. He underwent an arthroscopically aided reconstruction 2 weeks after the injury with hamstring autograft. After 1 weeks, he visited the physiotherapy clinic and at the time had trouble bending and straighten the knee, his thigh muscles seemed to shrink, and difficulty to walk. Rehabilitation is carried out one session a day, six days a week, included exercise to improve ROM, strength, and gait training.

Conclusion: This case suggests the exercise program provided can increase the range of motion of the knee joint after $\mathrm{ACL}$ reconstruction. Results of this case suggest a need for continued research with a larger group of patients with long-term evaluation is necessary to evaluate the safety and efficiency of exercise program in this case.

Keywords: ACL Reconstruction, Physiotherapy Management, Range of Motion (ROM)

Cite this Article: Ketiga, P.K., Putra, F.P. 2021. Physiotherapy Management on Anterior Cruciate Ligament (ACL) Reconstruction: A Case Report. Physical Therapy Journal of Indonesia 2(2):25-29. D0I: 10.51559/ptji.v2i2.28

support by magnetic resonance imaging (MRI) examinations. MRI can provide a clear picture to determine soft tissue injuries (ligaments, tendons, and meniscus). MRI has $95 \%$ sensitivity and $88 \%$ specificity on ACL tears diagnosis. ${ }^{4}$

An ACL rupture can be detected using a variety of clinical tests. With a claimed sensitivity of 85 percent and specificity of 94 percent, the Lachman test is the most accurate clinical diagnosis. ${ }^{5}$ For chronic ACL ruptures, the anterior drawer test has high sensitivity and specificity (92 percent and 91 percent, respectively), but it has a lesser accuracy for acute instances. ${ }^{5}$ The pivot shift test, if positive, is a strong indicator of an ACL rupture (98 percent specificity). Lachman test is performed with lying supine patient which involved extremity at the examiner's side. One hand examiner fixes the femur, the other hand is placed on the proximal posterior aspect of the tibia. The patient's knee position is bent 20-30 degrees then push forward. The test is positive if there is excessive anterior movement of the tibia. In the anterior drawer test, the patient lies supine with the hips bent at 45 degrees and the knees up to 90 degrees, the examiner stabilizes the patient's legs with their thighs and places both hands on the proximal tibia. Then the examiner 
applies anterior traction. The test is positive if there is excessive anterior translation of the tibia. For the pivot shift test, the patient is supine, the affected leg is lifted with the examiner fixating on the patient's ankle, then the patient's leg is rotated toward internal rotation and flexed the knee from a fully extended position while applying pressure to the valgus with the other hand on the proximal lateral side of the tibia. The test is positive if there is an anterior subluxation. ${ }^{5}$

Once the diagnosis is clear, the clinician should inform the patient of the injury and consequences that will occur. For many individuals, after ACL injured their knee will not feel like before the injury. Furthermore, an alarming proportion of people who have their ACL torn will acquire symptomatic knee osteoarthritis in their young to middle adulthood. ${ }^{6}$ Fear of re-injury is likely to be a role in many people's decision not to return to sport and instead embrace a physically sedentary lifestyle. ${ }^{7}$ However, not all individuals have poor outcomes after ACL rupture. This highlights the importance of identifying modifiable risk factors for poor outcome in ACL injured, and implementing personalized management strategies to optimize long-term outcome and quality of life. ${ }^{8}$

In the medical management of an ACL tear, an ACL reconstruction will usually be carried out by surgical procedure to graft the ACL using tendon tissue to restore joint fixation and stabilization function, this surgery can be done by arthroscopy. ${ }^{9}$ Several studies have shown that ACL reconstruction appears to be superior to conservative recovery for improving joint stability and helping to return to pre-injury levels of exercise. The right rehabilitation also have a great influences on the success of the post-reconstruction ACL. The first goal of an ACL rehabilitation program is to achieve full ROM in the knee joint after reducing inflammation. ${ }^{10}$ Therefore, the rehabilitation process can be done as early as possible with the following goals to increase muscular strength, restore joint mobility and neuromuscular control and help patients to return to normal activity levels in recovery process after ACL reconstruction. ${ }^{11}$

Physiotherapy rehabilitation programs are proven to be effective after reconstruction surgery of ACL. In general, these programs are designed to maximize function independence of the patient by restoring ROM, strength, and neuromuscular coordination. ${ }^{12}$ In the post-reconstruction conditions, physiotherapy management aims to prevent complications such as swelling, decreased joint range of motion, muscle weakness, decreased balance, and decreased functional ability of the knee. Based on previous research, isometric quadriceps workouts and straight leg lifts can be safely prescribed during the first two postoperative weeks, and provide benefits for quicker recovery of knee range of motion and stability. ${ }^{13}$ Therefore, in this case study, we discuss the early management of physiotherapy in cases of $\mathrm{ACL}$ reconstruction.

\section{CASE REPORT}

This case involves a 25 years old male who works as professional soccer player. He suffered an injury in February 2021 while training. The hip was in external rotation, knee extension, ankle dorsiflexion, and foot are everted. He was experiencing pain and instability over right knee at the time. Pain was gradually progressive in anterior of knee, which was getting aggravated by walking and relieved at rest, and associated with swelling. Then he came to the hospital for an examination and then an MRI was done which showed a total tear of the right ACL. The patient underwent surgery an ACL reconstruction using hamstring graft. Patient visited the physiotherapy clinic after 1 weeks and at the time he felt difficulty in bending and straighten the knee, his thigh muscles seemed to shrink, and difficulty in walking.

\section{METHOD}

\section{Measurement}

Evaluation of knee joint's range of motion was measured using a goniometer, the patient was asked to actively move his knee in the direction of knee flexion and extension. Restriction of motion and pain were found in the operated leg when compared to the healthy leg (Table 1). The range of motion of the hip joint of the patient who has not been able to move his leg optimally shows weakness of the right thigh muscle, which compared for the flexion and extension movements between the right (operated) and left knees (healthy leg).

Measurement of muscle atrophy using tape measure to assess the circumference of the segment showed $5 \mathrm{~cm}$ smaller difference in the operated leg compared to the healthy one (Table 2). As for the ankle joint, there is no limitation of motion when compared between the affected leg and the healthy leg, but there is mild pain when moving the right ankle.

Evaluation of leg muscle strength was measured using manual muscle testing (MMT) by instructing the patient to lift both legs actively alternately. The MMT values obtained in the operated leg are 2 for hip flexion, 3 for abductor hip, 3 for adductor hip, indicating a decrease in muscle strength when compared to healthy legs with an MMT value of 5 (Table 3). 
Table 1. Range of motion (ROM) assessment pre- and postinterventions

\begin{tabular}{lcc}
\hline \multicolumn{1}{c}{ Legs } & Pre-interventions ROM & Post-interventions ROM \\
\hline Right & $30^{\circ}$ & $90^{\circ}$ \\
Flexion & $10^{\circ}$ & $5^{0}$ \\
Extension & & \\
Left & $130^{\circ}$ & $130^{\circ}$ \\
Flexion & $0^{0}$ & $0^{\circ}$ \\
Extension & &
\end{tabular}

Table 2. Knee circumference pre- and post-interventions

\begin{tabular}{|c|c|c|c|c|}
\hline \multirow{2}{*}{ Circumference } & \multicolumn{2}{|c|}{ Pre-interventions } & \multicolumn{2}{|c|}{ Pre-interventions } \\
\hline & Right & Left & Right & Left \\
\hline $10 \mathrm{~cm}$ distal to SIAS & $49 \mathrm{~cm}$ & $54 \mathrm{~cm}$ & $50 \mathrm{~cm}$ & $54 \mathrm{~cm}$ \\
\hline $20 \mathrm{~cm}$ distal to SIAS & $45 \mathrm{~cm}$ & $50 \mathrm{~cm}$ & $46 \mathrm{~cm}$ & $50 \mathrm{~cm}$ \\
\hline $30 \mathrm{~cm}$ distal to SIAS & $48 \mathrm{~cm}$ & $44 \mathrm{~cm}$ & $45 \mathrm{~cm}$ & $44 \mathrm{~cm}$ \\
\hline
\end{tabular}

SIAS, spina iliac anterior superior

Table 3. Manual muscle testing pre- and post-interventions

\begin{tabular}{lcc}
\hline \multicolumn{1}{c}{ Legs } & $\begin{array}{c}\text { Pre-interventions } \\
\text { score }^{\mathbf{a}}\end{array}$ & $\begin{array}{c}\text { Post-interventions } \\
\text { score }^{\mathbf{a}}\end{array}$ \\
\hline Right & 2 & 3 \\
HIP Flexion & 3 & 3 \\
HIP Abductor & 3 & 3 \\
HIP Adductor & & \\
Left & 5 & 5 \\
HIP Flexion & 5 & 5 \\
HIP Abductor & 5 & 5 \\
HIP Adductor & & \\
\hline
\end{tabular}

${ }^{a}$ Manual muscle testing grades: 0 , no palpable muscle contraction or no visible movement; 1 , a slight palpable contraction, but no visible movement; 2 , visible movement, but it cannot against the gravity; 3 , full range of motion movement against the gravity without any resistance; 4 , full range of motion movement against the gravity with minimal resistance; 5 , full range of motion movement against the gravity with maximal resistance.

\section{Intervention}

Physiotherapy management in this case aims to increase the range of motion of the knee joint, increase muscle strength, and restore functional legs to improve activity daily activities. Rehabilitation is carried out of one session a day, six days a week, included exercise to improve range of motion (ROM), strength, and gait training (Table 4). Quadriceps setting exercise, this exercise aims to increase thigh muscle contraction (Figure 1). The patient seated against the wall, both legs are straight so that the hips form a $90^{\circ}$ angle, then instruct the patient to tighten his thigh muscles or press the back of the knee down, hold for 6 seconds and slowly return to the starting position. This exercise is done 6-10 times as tolerated. Straight leg raises multiplane exercise, this exercise aims to increase the strength muscle of hip, by straightening the knees and lifting the legs slowly then holding it for 3 seconds and slowly lowered. This exercise is performed in four directions of movement (flexion, abduction, adduction, and hip extension) without load, with 8-12 repetitions up to 3 sets.

Patellar mobilization, this exercise aims to increase mobility of patella, by towards the knee joint superior-inferior and medial-lateral to assist in achieving ROM of knee flexion and extension. This exercise is done 15-30 times as tolerated. Pelvic tilt exercise, to increase the mobility of hip joint by moving the pelvic forward and backward alternately with the same rhythm, this exercise is done 10-12 times in 3 set. Heel slide exercise, to increase ROM in the knee joint, the patient is instructed to sleep on his back with both legs straight, then the affected leg is moved towards knee flexion to the maximum extent that can be achieved then given a little external assistance to increase ROM in the knee joint and return to the knee extension position (Figure 2). Without stopping the movement, repeated 15-30 times up to 3 sets.

Ankle strengthening with theraband, which is an exercise using a resistance band on the ankle by providing resistance in each direction of ankle movement (plantar flexion, dorso flexion, eversion and ankle inversion). This exercise is performed 8-12 times for 3 sets. Weight shifting exercises, which aim to prepare the patient for walking. This exercise is performed in a standing position, the physiotherapist was behind the patient to maintain or help stabilize the patient while providing encouragement to the right-left, and front-back without any movement or leg shift. After that, he was given walking pattern exercises to help do the right gait pattern (Table 5).

In addition, the patient was instructed to do exercises on the healthy upper extremities and lower extremities to maintain ROM and muscle strength of a healthy extremity. To reduce inflammation and joint fluid effusion, cryotherapy (ice compresses) was administered for 15 minutes on the affected knee area.

\section{EVALUATION}

Patient was evaluated by a multidisciplinary team regularly to find out how the condition of the surgical wound is to prevent infection. After receiving physiotherapy treatment for two weeks, the results showed that decreased the edema on the knee, increased the range of motion of the 
knee joint (flexion: 90, extension: 5), no significant change in thigh circumference, no significant change in the MMT of the affected leg, but the patient's movements were increasingly controlled. The patient is able to walk without the help of a cane.

\section{DISCUSSION}

This case report indicates potential for recovery following ACL reconstruction. The exercise program is performed to minimize inflammation and the

Table 4. Interventions exercise for two weeks

\begin{tabular}{|c|c|c|}
\hline Exercise & Goal & Repetition \\
\hline Ice compress & Decrease swelling & $\begin{array}{l}10-15 \text { minute on affected } \\
\text { knee }\end{array}$ \\
\hline Quadriceps setting & Increase muscle contraction & $6-10$ times as tolerated \\
\hline Straight leg raises & $\begin{array}{l}\text { Increase muscle strength of } \\
\text { hip muscles }\end{array}$ & $8-12$ repetitions, 3 sets \\
\hline Patellar mobilization & Increase mobility of patella & 15-30 times \\
\hline Pelvic tilt & Increase mobility of hip joint & $10-12$ times, 3 sets \\
\hline Heel slide & Increase ROM of knee joint & $15-30$ times, 3 sets \\
\hline Ankle strengthening & $\begin{array}{l}\text { Increase muscle strength of } \\
\text { foot and ankle muscles }\end{array}$ & $8-12$ times, 3 sets \\
\hline Weight shifting & $\begin{array}{l}\text { Increase body awareness, } \\
\text { balance, and proprioception }\end{array}$ & 1 minute, 3 sets \\
\hline Gait training & Improve gait pattern & As tolerated \\
\hline
\end{tabular}

Table 5. Gait training pre- and post-interventions

\begin{tabular}{cl}
\hline \multicolumn{1}{c}{ Week } & \multicolumn{1}{c}{ Gait Training } \\
\hline Week 0 (pre-interventions) & Non-Weight Bearing (NWB) \\
Week 1 (post-interventions) & Partial Weight Bearing (PWB) \\
Week 2 (post-interventions) & Full Weight Bearing (FWB) \\
\hline
\end{tabular}
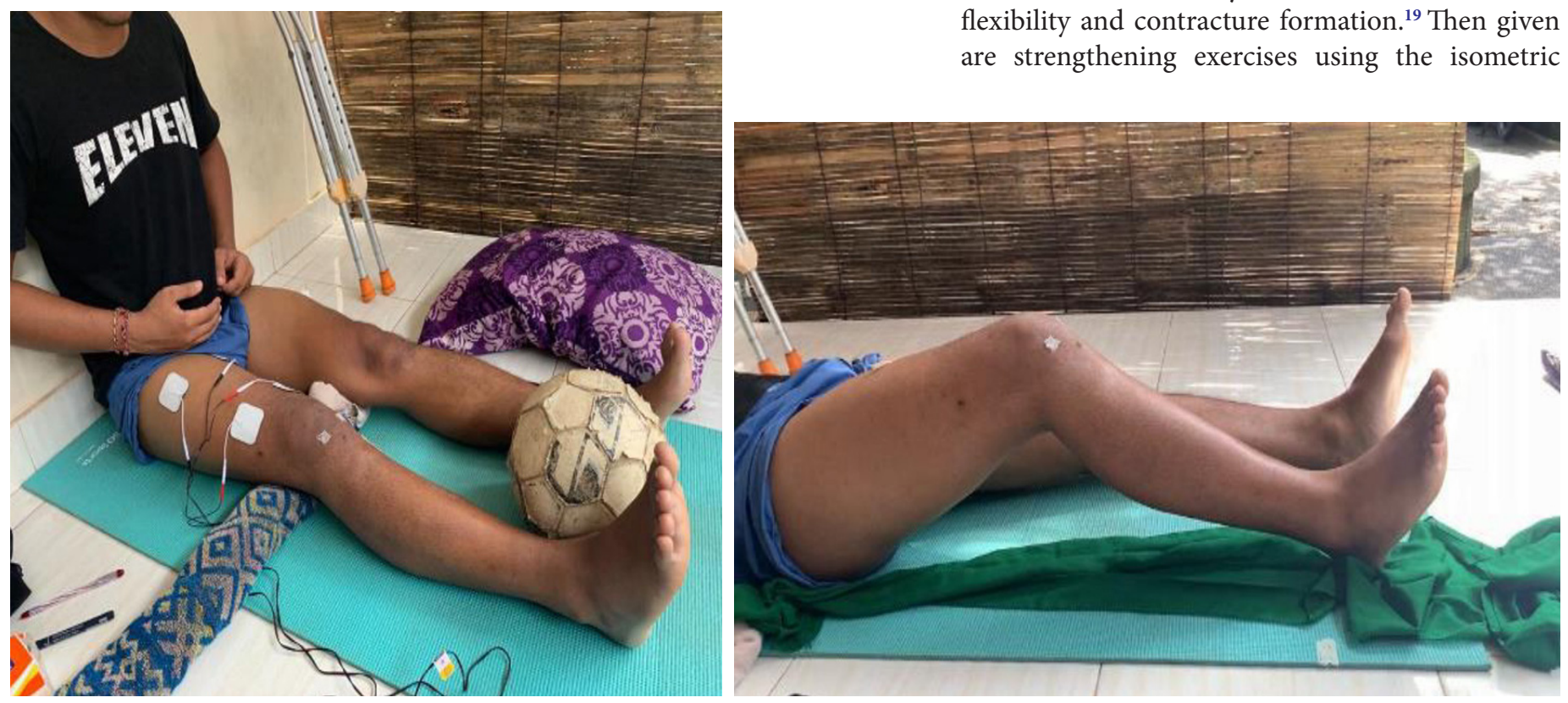

Figure 1. Quadriceps setting exercise effects of immobilization by initiating controlled mobilization and movement to allowhealing tissue to be stressed gradually and progressively until normal joint function returns. The exercise program should restore movement and proprioception, maintain cardiovascular fitness, and increase muscle strength and endurance. ${ }^{14}$ Therefore, the rehabilitation should be initiated immediately by doing active mobilization, extension postures (several hours per day, as tolerated), and repeated static quadriceps contraction. The goal of active mobilization is to develop neuromuscular control, endurance, and muscle strength. Long-term muscle immobilization would result in physical stress reduction that further causes contractile proteins shedding, decreases muscle fiber diameter, decreases the number of myofibril and intramuscular capillary density, and finally result in muscle atrophy and weakness. ${ }^{15}$ Previous studies suggest the goal of postoperative care is to recover basic lower limb functions, such as gait, knee mobility, and quadriceps strength. These active exercise have focus on the degrees of extension, because knee extension is usually required for activities (e.g., standing, walking). However, approximately $117^{\circ}$ knee flexion is necessary for some activities, such as squatting to tie a shoelace, pulling on a socks, or do prayers (shalat). ${ }^{16}$ Other activities, such as sitting in a chair requires approximately $90^{\circ}$ of flexion, and climbing stairs (average height) requires approximately $80^{\circ}$ of flexion. ${ }^{17}$ Other studies reported that impaired ROM after ACL reconstruction, especially extension, was very detrimental to quadriceps muscle strength. ${ }^{18}$

The ROM exercises are given to maintain joint and soft tissue mobility to minimize loss of tissue flexibility and contracture formation. ${ }^{19}$ Then given are strengthening exercises using the isometric
Figure 2. Heel slide 
method, where the muscles contract without changing the length of the muscles or movement of the joints. Isometric quadriceps exercise and straight leg raises performed safely during the first two weeks postoperatively resulted in small but statistically significant improvement in the recovery of range of motion and frequency of knee stability. Besides being able to increase muscle strength, the effect of this exercise is to pump blood vessels back, so that metabolism is smooth and can reduce swelling. ${ }^{20}$

\section{CONCLUSION}

This case suggests that the exercise program provided can increase the range of motion of the knee joint after ACL reconstruction. Inability to perform long term patient follow up are affected by limited time and opportunity, and lack of documentation on physical therapy management on the first day after surgery are several limitations in our case report that result in inadequate evaluation report on patient intervention and outcome. It is hoped this case can be used as a reference for the initial phase of ACL rehabilitation, so that immobilization does not occur again after ACL reconstruction. Further research with a larger group of patients with longterm evaluation is necessary to evaluate the safety and efficiency of exercise program in this case.

\section{ACKNOWLEDGEMENT}

The authors want to thank the Bali United Football Club in Bali, Indonesia for the work experience and the permission to report this study. This work received no funding from any institution.

\section{CONFLICT OF INTEREST}

No commercial party having an interest in the subject matter of this research will give a benefit on the authors or on any affiliation with which the authors are associated.

\section{AUTHOR CONTRIBUTIONS}

PKUK conceived the study design and data collection and drafted the manuscript; FPP drafted the manuscript.

\section{REFERENCES:}

1. Kan S, Yuan Z, Ning G, Yang B, Li H, Sun J et al. Autograft versus allograft in anterior cruciate ligament reconstruction. Medicine. 2016;95(38):e4936.

2. Wiratna AY. Penatalaksanaan Fisioterapi Pada Kasus Post Operative Ruptur Anterior Cruciate Ligamen (ACL) di RS AL. Dr Ramlan Surabaya. FIKES UMS. 2015.

3. Gans I, Retzky J, Jones L, Tanaka M. Epidemiology of Recurrent Anterior Cruciate Ligament Injuries in National
Collegiate Athletic Association Sports: The Injury Surveillance Program, 2004-2014. Orthopaedic Journal of Sports Medicine. 2018;6(6):232596711877782.

4. Helito C, Demange M, Bonadio M, Tírico L, Gobbi $\mathrm{R}$, Pécora $\mathrm{J}$ et al. Anatomy and Histology of the Knee Anterolateral Ligament. Orthopaedic Journal of Sports Medicine. 2013;1(7):232596711351354.

5. Benjaminse A, Gokeler A, van der Schans C. Clinical Diagnosis of an Anterior Cruciate Ligament Rupture: A Meta-analysis. Journal of Orthopaedic \& Sports Physical Therapy. 2006;36(5):267-288.

6. Øiestad BE, Engebretsen L, Storheim K, Risberg MA. Knee osteoarthritis after anterior cruciate ligament injury: a systematic review. Am J Sports Med 2009;37(7):1434e43.

7. Ardern CL, Taylor N, Feller J, Webster K. A systematic review of the psychological factors associated with returning to sport following injury. Br J Sports Med 2012 Nov;47(17):1120e6.

8. Filbay SR and Grindem H. Evidence-based recommendations for the management of anterior cruciate ligament (ACL) rupture. Best Practice and Research Clinical Rheumatology. 2019 Feb; 33(1): 33-47.

9. Canale, ST, Beaty JH. Campbell's Operative Orthopaedics. Philadelpia : Elsevier Health Sciences. 2012;8(1).

10. Mangine G, Ratamess N, Hoffman J, Faigenbaum A, Kang J, Chilakos A. The Effects of Combined Ballistic and Heavy Resistance Training on Maximal Lower- and UpperBody Strength in Recreationally Trained Men. Journal of Strength and Conditioning Research. 2008;22(1):132-139.

11. H. Vernon, Matthew Selby. Case Study Rehabilitation of an ACL injury in a 29 year old male with closed kinetic chain exercises. 2019

12. J A Feller, K E Webster, NF Taylor. Effect of physiotherapy attendance on outcome after anterior cruciate ligament reconstruction: a pilot study. 2004;38(1):74-7.

13. Shaw T, Williams MT. and Chipchase LS. Do early quadriceps exercises affect the outcome of ACL reconstruction? A randomized controlled trial. Australian Journal of Physiotherapy. 2005; 51: 9-1

14. Anderson MK, Parr GP, \& Hall. Foundation of Athletic Training. Philadelphia: Wolters Kluwer Health/Lippincott Williams \& Wilkins. 2009;4.

15. Pujol N, Boisrenoult P, Beaufils P. Post-Traumatic Knee Stiffness: Surgical Techniques. Orthopaedics and Traumatology: Surgery and Research. 2015;101: S179-S186.

16. Morri M, Forni C, Ruisi R, Giamboi T, Giacomella F, Donati DM, Benedetti MG. Postoperative Function Recovery in Patients with Endoprosthetic Knee Replacement for Bone Tumour: an Observational Study. BMC Musculoskeletal Disorders. 2018;19(353): 1-7 11.

17. Magee DJ. Orthopedic Physical Assessment. 6th ed. Canada: Elsevier; 2014

18. Noll S, Garrison J, Bothwell J, Conway J. Knee Extension Range of Motion at 4 Weeks Is Related to Knee Extension Loss at 12 Weeks After Anterior Cruciate Ligament Reconstruction. Orthopaedic Journal of Sports Medicine. 2015;3(5):232596711558363.

19. Santoso I, Sari IDK, Noviana M, Pahlawi R. Penatalaksanaan Fisioterapi Pada Post Op Rekonstruksi Anterior Cruciate Ligament Sinistra Grade III Akibat Ruptur di RSPAD Gatot Soebroto. Jurnal Vokasi Indonesia. 2018;6(1):66-80

20. Kisner C \& Collby LA. Therapeutic Exercise: Foundation and Techniques. 5th ed. Philadelpia: FA Darwis Company. 2007.

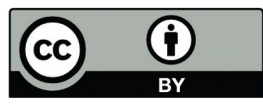

This work is licensed under a Creative Commons Attribution 